\title{
Las condiciones del aprendizaje escolar, las culturas juveniles y uso de TICs en el ingreso a la Escuela Media: los problemas en la transmisión entre jóvenes y profesores
}

Alejandro Villa*

\section{Resumen}

Se estudian las problemáticas de la relación entre culturas juveniles y el aprendizaje, así como los procesos transmisión entre jóvenes y profesores, en el primer año de la Escuela Media. Se trata de un diseńo cualitativo de casos estudiados en profundidad. El mismo comprende una comparación entre jóvenes y profesores. Se utilizan las técnicas de la entrevista semiestruturada y el grupo de discusión. Los objetivos generales son explorar y describir los significados que adquieren para las identidades juveniles la incorporación de los medios de comunicación masiva, así como el consumo y producción de culturas juveniles y el impacto que introducen dichos significados en los procesos de transmisión generacional entre los docentes y los jóvenes. A partir de los resultados, se proponen tres discusiones: la masificación que comporta para los jóvenes el consumo de culturas juveniles en el primer año de la Escuela Media, no permite visualizar y podría encubrir las relaciones de violencia interpersonal y de desigualdad entre ellos mismos, así como sus posiciones de productores culturales; existe para los jóvenes una marcada disociación en el aula, entre, por un lado, las interacciones entre pares y consumo/producción de culturas juveniles, y, por otro, la cultura escolar y el proceso de aprendizaje; la problemática de atención/desatención de los jóvenes en el proceso de aprendizaje en el aula, está vinculada con el proceso de transmisión que se produce entre docentes y estudiantes en el ingreso a la Escuela Media.

Palabras claves: Pedagogía. Culturas juveniles. Escuela Media.

\footnotetext{
* Investigador Asociado del Consejo de Investigación en Salud (2001 hasta la actualidad), Ministerio de Salud/Gobierno de la Ciudad de Buenos Aires. Investigador adjunto, Instituto de Investigaciones Gino Germani, Facultad de Ciencias Sociales/UBA. Investigador principal del Instituto Universitario de Ciencias de la Salud (IUCS), Facultad de Psicología/ Fundación Universidad Barceló.
} 


\section{Contextualización y formulación del problema de estudio}

Algunas perspectivas pusieron de relieve en la región latinoamericana, lo que denominaron la "experiencia cultural" de fines del siglo XX. Particularmente, Martín Barbero (1998) propuso profundizar en lo que denominó tres "atmósferas culturales". En primer, lugar la "tecnofascinación", donde convergerían la sociedad de mercado y una racionalidad tecnológica, junto con un debilitamiento de los valores de las personas. En segundo lugar, se trata de "la secularización y el desencanto", caracterizados por el desengaño respecto de la política, la que transforma el espacio público en un espacio publicitario. $\mathrm{Y}$ en tercer lugar se trata de la atmósfera de la "desintegración del horizonte sociocultural común". Allí el "horizonte cultural de la nación” es disuelto por los medios de comunicación; los que privilegian la producción de una heterogeneidad de imaginarios, que juntan lo global con lo local. Las redes mediáticas "vehiculizan una multiculturalidad que hace estallar los referentes tradicionales de identidad".

También Garcia Canclini (1995, p. 41) define al consumo como "el conjunto de procesos socioculturales en que se realizan la apropiación y los usos de los productos". Asimismo, "todos los actos de consumo son hechos culturales, pero la distinción de consumos culturales *se justifica debido a la parcial independencia lograda por los campos artísticos e intelectuales en la modernidad*”. Es decir, en los consumos culturales en sentido específico, "prevale el valor de simbólico por sobre los valores de uso y de cambio" (GARCIA CANCLINI, 1999 apud MINISTERIO DE EDUCACIÓN-PRESIDENCIA DE LA NACIÓN-CONECTAR IGUALDAD, 2012, p. 17-18).

Existe cierto consenso en la literatura de las ciencias sociales de los años 2000, en caracterizar a las "culturas juveniles" en tanto "las formas mediante las cuales los jóvenes participan en los procesos de creación y circulación culturales", así como "la relación/tensión" de estas formas con la construcción cultural que hace cada sociedad de las maneras de ser joven, en tanto dimensión estructural que se les asigna a los jóvenes allí (VILLA; INFANTINO; CASTRO, 2012, p. 17).

Esta tensión entre las prácticas culturales juveniles y las "imágenes culturales" que asignan las sociedades a los jóvenes, puede ser entendida como un conflicto de poder entre imágenes: aquellas hegemónicas que producen las instituciones, los medios de comunicación en torno a las prácticas y consumos juveniles, y por otro, las prácticas culturales de los jóvenes. Ello supone considerar dos dimensiones: el análisis de las imágenes que configuran el mundo cultural del que participan los jóvenes, así como la dimensión política por la disputa de sentido entre dichas imágenes y las que producen la sociedad y sus instituciones. 
Además, si enfocamos el contexto de la transición educativa entre la Escuela Primaria y Media, es escaso el conocimiento que se ha producido para describir el proceso de construcción identitária de los jóvenes en tanto grupos sociales y culturales.

En el campo de la sociología de la educación surgió una perspectiva que se propuso debatir un "desajuste entre socialización y subjetivación” en los procesos de individuación de los jóvenes en el ingreso a la Educación Media. Dubet y Martuccelli (1999, p. 435) discuten "un triple estallido de la socialización" en el ingreso a la escuela secundaria: "un universo normativo complejo" de la escuela que pone en juego la capacidad de ajuste de comportamientos diversos de los adolescentes; "el estudio no vale por sí solo" y las "clasificaciones" determinan el "futuro" de las trayectorias escolares juveniles; "la consolidación de una cultura adolescente en la escuela, paralela a la cultura escolar". Por un lado, se produce una "alienación" de los jóvenes en el sistema escolar; y por otro, la misma crea una "distancia entre la socialización y la subjetivación" de los jóvenes en sus experiencias escolares (DUBET; MARTUCCELLI, 1999, p. 440). Los jóvenes definen al mismo tiempo sus experiencias de aprendizaje como un proceso ajeno a ellos mismos, y por otro, experimentan la relación con sus pares y el consumo/producción de culturas de masas como algo propio de sus subjetividades. Siguiendo esta perspectiva, en un estudio previo sobre la transición de la escolaridad primaria a la media en los sectores populares urbanos de extrema pobreza, realizado con jóvenes y docentes, hemos discutido las diferentes concepciones de éstos y los procesos de transmisión que se ponen en juego en el aula (VILLA, 2012).

Dicho "estallido de la socialización" de los jóvenes en el ingreso a la escolaridad media, supone enfocar y analizar con detenimiento la tensión y posibles articulaciones entre, por un lado, las culturas escolares y el aprendizaje, y por otro, el consumo/producción de bienes materiales y simbólicos en las prácticas y culturas juveniles, en el escenario escolar. Nos interesa analizar allí a la escuela como un territorio de disputas culturales, así como de procesos de reconocimiento identitário de los jóvenes y los adultos en la relación pedagógica.

Buckingham (2003), desde el campo de la educación en medios, viene proponiendo una problematización de la noción de "consumidor cultural". Se discute que dicha noción es inseparable de la de "productor de imágenes". Esto supone discutir nuestros supuestos como parte de un "ideologismo del pensamiento crítico", entendido como una concepción del aprendizaje "conciente, crítico y discursivo”.

Asimismo consideramos necesario profundizar en los mecanismos de transmisión que se ponen en juego en las relaciones de generación: ¿Qué imágenes, de qué modo y bajo qué regímenes, se ponen en emisión y recepción en la relación entre jóvenes, entre jóvenes y adultos en la escuela? 
La noción de "espectador emancipado" (RANCIERE, 2010) nos puede permitir la posibilidad de poner en acto un mecanismo de traducción y narración entre diferentes órdenes de imágenes. Por un lado, las imágenes que ponen en juego los jóvenes, y por otro, los docentes, en el ámbito escolar y la relación pedagógica, en particular.

Nuestro problema de estudio está constituido por las formas de intervención del consumo de los medios masivos de masivos de comunicación y la producción de diferentes culturas juveniles en dicho proceso de construcción identitária de jóvenes en formación, tomando como referencia la relación de los jóvenes con sus pares y con los docentes, en el primer año de la escolaridad media.

- ¿De qué modos las concepciones de los jóvenes, en proceso de formación de identidades en el momento del ingreso a la Escuela Media, incorporan los repertorios simbólicos de los medios masivos de comunicación y el consumo de culturas juveniles?

- ¿Qué significados tienen para las identidades juveniles allí la utilización de las TICs, y las prácticas culturales?

- ¿Cómo impactan la utilización de las TICs y las prácticas culturales juveniles en los procesos de transmisión entre las generaciones, considerando los vínculos entre pares, la relación con los adultos en el ámbito de la escuela?

- ¿Qué cuestionamientos introduce el papel de los medios de comunicación de masas y las culturas juveniles en la relación pedagógica con los docentes, en cuanto al modo de concebir a los/as jóvenes, en tanto sujetos de educación?

Este trabajo forma parte de un estudio más amplio ${ }^{1}$, cuyo objetivo general fue explorar y describir, por un lado, los significados que adquieren para las identidades juveniles la incorporación de los medios de comunicación masiva, así como el consumo y producción de culturas juveniles, en el ingreso a la Escuela Media. Pero también, explorar y describir el impacto que introducen dichos significados en los procesos de transmisión generacional con los docentes con los que interactúan los/as jóvenes en el momento del ingreso a la Escuela Media.

\section{Metodología de estudio}

Realizamos un estudio cualitativo, de casos estudiados en profundidad, de tipo exploratorio y descriptivo, así como de carácter inductivo.

Se trata de un estudio comparativo de las percepciones juveniles y las de los docentes con los que los jóvenes están en interacción, durante el primer año de la 
escuela secundaria. Para ello, se recabó información en poblaciones de Escuelas Medias de la zona sur de la Ciudad de Buenos Aires (CABA), en las que concurre población de sectores populares urbanos más empobrecidos de la CABA².

Las unidades de análisis de nuestro estudio son jóvenes de dicha población, de ambos sexos, que ingresan y se encuentran cursando el primer ańo de la Escuela Media; así como docentes de Escuelas Medias, que trabajan con dicha población.

Se trabajó con dos técnicas cualitativas de recolección de datos: la entrevista semi-estructurada (MILES; HUBERMAN, 1994) y el grupo de discusión (IBAÑEZ, 1994). En el primer caso, se diseñó un instrumento que contemplaba todos los tópicos de nuestro estudio. La misma fue aplicada a jóvenes y profesores de ambos sexos. En el segundo caso, se realizaron grupos de discusión con los mismos tópicos, con seis encuentros mensuales, a lo largo del primer ańo de la escolaridad.

El grupo de estudio quedó conformado por: a) La realización de 10 entrevistas a jóvenes y otras diez a docentes; b) Cuatro grupos de discusión con jóvenes ${ }^{3}$.

La información de las entrevistas fue grabada audiofónicamente, previo consentimiento informado de los participantes. Luego fueron desgrabadas y sometidas a un proceso de codificación cualitativa con el software Atlas Ti.

El proceso de los grupos de discusión fue registrado en crónicas con personal designado a tal efecto. Luego, se procedió a analizar los registros escritos según los mismos tópicos y códigos utilizados para la realización de las entrevistas.

\section{Las transformaciones en la identidades y en las interacciones con los pares}

Uno de los principales ejes temáticos indagados, tanto con jóvenes como con profesores/as, lo constituyó la percepción de cambios que tenían los jóvenes de sí mismos al ingresar a la Escuela Media, con respecto a percepción de sí mismos en la escolaridad primaria.

Lo que primero se destaca en los jóvenes es una dificultad para hablar o percibir dichos cambios. No obstante ello, en las entrevistas se produce una reflexividad que destaca las características personales personalidad de sí mismo. Son recurrentes las afirmaciones: "es igual" o "yo cambié, soy más grande", "cambiar la timidez y hablar más", "saber defenderse cuando te dicen cosas", "aprender a hablar mal y putear, antes era otro el que te defendía". Es importante notar que dichos cambios se presentan disociados de la relación pedagógica. Cuando se mencionan los cambios en la escolarización (por ejemplo, cantidad de materias y profesores, tipo de exigencia 
académica, tipo de vínculo con profesores/as, régimen disciplinario), ellos se presentan como algo externo a la subjetividad juvenil. Esta relación con la escuela y con los/as profesores/as se destaca más en el proceso de los grupos de discusión.

En el caso de los/as profesores/as estudiados/as, la mayoría visibiliza que en un primer momento, la escuela media se presenta como algo extraño a los/as jóvenes y que éstos/as "son muy chiquitos" frente a las exigencias de aquélla ${ }^{4}$. Una afirmación común que encontramos es "los chicos tienen miedo e inseguridad y se sienten vulnerables" y que por ello, se argumenta que la descalificación de sus pares surge como un primer "mecanismo defensivo".

Cuando indagamos sobre las interacciones entre los/as jóvenes y la conformación de grupos, la primer categoría emergente para los/as jóvenes que se presenta como un ordenador es el par desconfianza/confianza. Partimos de una desconfianza vincular inicial relacionada con una serie de dimensiones.

Para los jóvenes tiene especial importancia la discriminación y el ejercicio de la violencia según el barrio de procedencia ${ }^{5}$. Es el hecho relatado a menudo de pelearse y enfrentarse entre diferentes barrios, el "ir a buscar bronca".

Una segunda dimensión, alude a una "desconfianza vincular", personalizada en algunos/as compañeras del curso. Esta puede adquirir varias formas. En primer lugar se resalta la preocupación de que el compañero o compañera hable por detrás de uno/na mismo; de ahí que la expresión de la intimidad puede volverse en contra de un mismo joven. Son recurrentes las afirmaciones del tipo "vos le contas algo a...y después le cuentan a otros y todos te cargan o te bardean". En segundo lugar, la mayoría de los/as jóvenes pueden identificar, que algunos compañeros/as se hacen los/as malos/as del grupo ante todo el curso para buscar "ser respetados" ante los pares y también ante los profesores. Se trata del ejercicio de la violencia mediante el insulto, la violencia física, o más atenuado, la burla entre pares, constituida por el cargarse. Pero también es común el robarse elementos o romper algo del/de la compañero/a; luego que incluso alguien prestó un objeto propio. Llama la atención que las mujeres, y también los varones, destaquen más el hecho de que sus compañeras se hacen las malas y ejerzan violencia entre ellas y con los/as profesores/as, comparadas con la declaración acerca de que son los varones los que se hacen los malos con respecto a sus pares. Esto podría hacernos pensar en una mayor necesidad de las mujeres de búsqueda de respeto ante sus pares y la institución escolar mediante la violencia en el aula y la escuela y/o una naturalización de la violencia por parte de los varones allí, hacia sus pares del mismo sexo y hacia las mujeres.

El modo de operar de esta desconfianza acentuaría un proceso de retraimiento y aislamiento de los/as jóvenes, o una exacerbación del ejercicio de la violencia como modo de vinculación con sus pares en la escuela. 
Pero, junto a esta desconfianza, y al mismo tiempo, se producen procesos que involucran el establecimiento de la confianza en los vínculos entre pares. En esta dirección, existen una serie de hechos señalados por los/as jóvenes que van a conformar un proceso. Uno de aquéllos lo constituye el comenzar a compartir la realización de la tarea escolar en grupo en el aula. También la mayoría destaca el hecho de escuchar música juntos en el recreo y compartir los juegos mediáticos (actividad que predominantemente reúne a los varones y no a las mujeres) y conectarse a face con las computadoras personales (netbook). Además, el hecho de "joder y cargarse" entre pares y los/as profesores/as, que en principio no es percibido como un hecho de "compartir" sino como una expresión de individualidades en interacción, luego se transforma también en una actividad que comparten los/as jóvenes en pequeños grupos. Finalmente, luego de la mitad del primer año de escolaridad, la mayoría afirma que conoció nuevos amigos y que se conformaron grupos, que comparten salidas, luego del horario escolar. Es importante destacar, que en las entrevistas y en los encuentros grupales realizados hacia fines del primer año escolar, muchos/as jóvenes pueden reconstruir mediante su reflexividad individual e incluso en el proceso grupal, todos estos hechos que involucraran al par desconfianza/confianza, en tanto proceso, al que aluden como el pasaje de "pelearse" a luego "llevarse bien" en el grupo de toda la división.

En cuanto a la percepción de los/as profesores/as sobre la interacción entre los/as jóvenes y la conformación de grupos, algunas cuestiones coinciden con las percepciones juveniles, y otras, no.

La primera cuestión señalada, en orden de importancia por la mayoría es el hecho que los/as jóvenes, al iniciar la Escuela Media, se agrupan en el aula por sexo, nivel escolar, por barrios y escuelas de procedencia. Junto a ello, destacan la diferenciación de los/as jóvenes según "el tipo de apoyo familiar"6. También señalan que esta agrupación puede suponer una "pérdida de pautas trabajo escolar previas". Pensamos que este último argumento abona a la idea acerca de que la Escolaridad Media significa un nuevo proceso de socialización para los jóvenes que rompe abruptamente con las pautas de la escolarización primaria (VILLA, 2012). Además, es de consenso general entre los docentes la consideración de escuela media como "continente social" para los jóvenes. Esto es descripto en términos de la escuela como lugar de pertenencia social y cultural juvenil, pero que relega lo educativo, con la propia aceptación de docentes y de la institución ${ }^{7}$.

La segunda cuestión señalada, coincide en parte con la categoría juvenil hacerse los/as malos/as. La mayoría de los docentes argumenta que los/as jóvenes se agrupan en torno a un líder que "rompe el encuadre del aula"; al cual se "copia". Según la explicación formulada por estos docentes, se establecería así un proceso identificatorio 
con jóvenes que son disruptivos con el aprendizaje escolar; los cuáles son tomados como ideales por sus pares. Asimismo, este proceso identificatorio actuaría negativamente sobre aquellos jóvenes que quieren estudiar; configurándose un "hostigamiento grupal al que estudia".

También los/as docentes destacan la percepción del ejercicio de la discriminación de género de los chicos a las chicas y que éstas invaden interacciones exclusivas entre varones. No obstante ello, no se declara en general la discriminación y violencia específica, que involucra a los varones entre sí, cómo sí lo hacen los jóvenes varones estudiados. Cabría preguntarse si esto no es una invisibilización en la práctica docente, que podría operar no estableciendo una discusión de género en el aula frente a la violencia entre varones.

Además, es generalizada la percepción docente acerca de la existencia de un rechazo a las diferencias culturales entre los mismos jóvenes (de orden étnico y de gustos culturales en torno a las subculturas juveniles). Los docentes argumentan que estas situaciones de discriminación cultural se contraponen con una suerte de "homogeneización cultural" que comportaría el uso de las TICs entre jóvenes, a partir del uso de las redes sociales y la música.

También, algunos docentes expresan que los jóvenes demandan una autoridad de tipo disciplinar frente a los conflictos con los pares, por situaciones de violencia y discriminación y que los/a profesores tienen dificultades para poner límites a estas situaciones. Observamos frente a ello dos posiciones en sus opiniones. Por un lado, "dejar pasar la violencia", por no considerarla parte de su rol docente; y por otro, aquéllos que tratan de habilitar la comunicación y abordar la desconfianza entre los/as jóvenes.

\section{Proceso pedagógico y culturas juveniles en el ingreso a la Escuela Media}

A continuación, describimos un conjunto de hallazgos vinculados a la percepción que tienen los jóvenes sobre los cambios y características de la relación con los profesores en la escuela media con respecto a la escolaridad primaria.

El primer hallazgo que destacamos es que la mayoría de los/as jóvenes afirman no percibir cambios en la relación con los docentes, aun cuando afirman al mismo tiempo, pero en segundo orden de importancia, que hubo un cambio constituido por la multiplicación de profesores en la escuela secundaria con respecto a la primaria. Parece acontecer, que ante nuestra pregunta explícita que aludía a la comparación con la 
finalización de la trayectoria educativa de la escolaridad primaria, los cambios son percibidos como una posición personal del/de la joven que no incorpora el efecto de la escolarización media. Ellos/as no se percibirían cambiando personalmente frente sus docentes, aun cuando puedan reconocer las determinaciones institucionales que "les impone" la Escuela Media ${ }^{8}$.

Ello se corresponde con las discusiones de Dubet y Martuccelli (1999), señaladas por nosotros en el inicio de este artículo: los/as jóvenes disocian inauguralmente sus condiciones de individuación de las determinaciones de la cultura escolar. Agregaríamos nosotros la hipótesis, además, de la búsqueda de un control personal del joven en lo que está aconteciendo en la relación pedagógica, en tanto proceso "exterior" a las subjetividades juveniles.

La segunda cuestión que queremos discutir, está relacionada a una segunda categoría emergente, que se presenta en la mayoría de los jóvenes: no prestar a atención en algunas materias y distraerse con amigos. El argumento juvenil hegemónico sostiene que "los que se llevan materias distraen a los otros que estudian y los profes los sacan del aula". Analizando este argumento, consideramos que la misma puede operar, al menos, en tres dimensiones de significados.

En una primera dimensión, como ya hemos discutido en un estudio anterior, esta categoría podría operar como efecto de la selección meritocrática de la institución escolar en el aula, siguiendo a Bordieu en Francia y a Kaplan y Llomomate en Argentina (VILLA, 2012), se trata de una práctica docente performativa en la relación pedagógica que clasifica a sus estudiantes. Pero también, siguiendo a Dubet y Martuccelli (1999), se trata de la incorporación personal de la posibilidad cierta del fracaso como interiorización de dicha desigualdad impuesta por el sistema escolar.

En una segunda dimensión, "distraerse" pone en cuestión qué se está produciendo en el proceso de transmisión en la relación pedagógica. ¿Qué ofrece el docente allí? ¿Qué ponen en juego los jóvenes? Ranciere (2010), se interroga por las posibilidades de las inteligencias del docente y su alumno de colocarse en transmisión, en relación a la categoría de reconocimiento del otro. Nosotros nos preguntamos ¡existe acá una acción de reconocimiento de la inteligencia del otro? Discutimos previamente las categorías juveniles acerca de que los docentes son aburridos y que hablan mucho, dando a entender que los textos pedagógicos guardan poca relación con los textos de las culturas juveniles. También afirmamos allí que en la escolaridad primaria los docentes ofrecen textos curriculares, y una relación personalizada, pero disociada del proceso de aprendizaje (VILLA, 2012). En otro trabajo propusimos, además, que cuando los docentes ponían en juego algo del orden de la narración y de su deseo por transmitir, las cosas podrían funcionar en cuanto a los efectos de sentido (VILLA, 2009). 
En una tercera dimensión, damos la razón al argumento compartido por docentes y jóvenes: "los estudiantes no ponen atención en el aprendizaje porque priorizan la interacción con sus pares". Allí está presente la categoría del otro que distrae mi aprendizaje. Nótese que cuando el estudiante interioriza el fracaso escolar, ello no es algo experimentado en términos de una subjetivación propiamente dicha del joven. Es "algo propio" y es "del otro que me induce", al mismo tiempo. Subsiste la ambivalencia de esta disociación que operaría la socialización escolar.

El tercer hallazgo en el que está implicada la transmisión, está constituido por el hecho de que los jóvenes le preguntan al profesor cuando no entienden algún tema y el profesor no explica bien. Según estas perspectivas el docente supone que sus estudiantes tienen que tener conocimientos previos sobre algún tema. Allí surge la escolaridad primaria en la memoria como algo del orden del conocimiento transmitido y valorizado: "En la primaria explicaban, ahora, no". Junto a ello, en la escolaridad actual, la mayoría relatan una suerte de "intermitencia" en la escucha al profesor de la escuela media: "a veces sí, a veces no" (escucho) ${ }^{9}$. Las referencias de las entrevistas y de los grupos con los/as jóvenes apuntan al reconocimiento de una suerte de "gramáticas" diferentes en la transmisión y a una atención diferente puesta por los/a jóvenes, comparando la escolaridad primaria y la secundaria.

Estas preguntas del joven por su no saber en el contexto grupal de la clase, "delante de todos", también se transforma en una demanda personalizada al docente de que les expliquen los contenidos curriculares. Esta demanda es contrapuesta por los jóvenes, al hecho de tener que mostrar su no saber frente a los pares cuando los/as profesores/as los hacen pasar al pizarrón frente al aula y que sus pares los cataloguen de burros $^{10}$. Existe allí una tensión entre el anonimato del joven en la clase masiva y su demanda personal al profesor por un lado, y la exposición de su no saber delante de los otros, los pares, por otro. Ello tiene importantes efectos en la validación de la autoridad de los docentes para los/as jóvenes: se respeta a aquel/la profesor/a que busca hacerse escuchable ${ }^{11}$. Ello alude a aquél docente que puede explicar un conocimiento en el aula y particularmente, que tenga una capacidad de generar un efecto personal en el joven. No se trata, de "algo para todos", lo que es percibido como impersonal y "des-subjetivante" en las perspectivas juveniles ${ }^{12}$.

Un cuarto hallazgo, está constituido por el hecho de que muchos jóvenes identifican un cambio en el lugar del afecto en la relación pedagógica. Se experimenta que en la escuela primaria, tanto los estudiantes como sus maestros tenían más permitido expresar afectos y reconocimientos mutuos personalizados, que en la escuela media. No obstante ello, muchos jóvenes aluden a la construcción progresiva de un vínculo de confianza con los profesores de la secundaria: "compartir cosas" y "reírse juntos". 
En quinto lugar destacamos algunos significados de la categoría respeto. La mayoría se siente respetado por los profesores, mientras que algunos/as, no. En este último caso, relatan situaciones de "discriminación" que experimentaron ellos/as mismos/as u otros jóvenes por parte de algún/a profesor/a particular, cuando intervienen frente a una transgresión de algún estudiante. La categoría utilizada es el bardeo del profesor: ella se refiere a que el profesor utiliza los mismos términos que los jóvenes para dirigirse, del orden del insulto, a alguno en particular o que realizan algún comentario irónico en medio de la clase frente a sus compañeros. Esto es percibido como una "injusticia" y genera discusiones y peleas verbales, de tono violento, con el docente en el aula. Queremos destacar que lo que parece generar malestar y enojo en los jóvenes no es el hecho de ser sancionados, sino que un profesor no reconozca la diferencia de "mundos culturales" del docente y de ellos: es el hecho de que el docente se ponga en la misma posición cultural que sus estudiantes. También en este contexto, los/as jóvenes afirman que las sanciones que practica el docente, en la escuela media se individualizan, a diferencia de la primaria, donde se "castiga" a todo el grupo cuando alguien individualmente realiza alguna transgresión. Esto lo relatan en un tono de reconocimiento y aceptación de las normativas escolares. Habría que profundizar aquí en los límites entre la "transgresión a normas escolares" y el reconocimiento de diferencias culturales, que se pondría en juego en la definición de la categoría de respeto.

Del análisis de las perspectiva de los/as profesores/as surgen las siguientes argumentos como los principales elementos que intervienen en la construcción del vínculo pedagógico.

La primera cuestión destacada por la mayoría alude al impacto en los/as jóvenes del ingreso a la secundaria en tanto un "quiebre". El principal indicador para ellos es que no hay "gestión del estudio" por parte de los jóvenes. También la mayoría reconoce el problema que significa para los jóvenes la gran cantidad de docentes que procuran imponer diferentes exigencias y demandas a los jóvenes. En lugar de profundizar en este problema, aparecen las críticas generalizadas a la herencia del "deficitario aprendizaje de la escuela primaria”. Ellos se detienen y quedan en la identificación del problema de cómo se sitúa el profesor de la escuela media frente a dicha herencia del aprendizaje, ahora considerado en relación a su enseñanza. Se manifiesta que los/as jóvenes necesitan que alguien los "ordene" en el ingreso a la secundaria. Allí se rescata la figura del profesor tutor, que tiene como objetivo la gestión del estudio en el aula.

La segunda cuestión, que preocupa generalizadamente a los/as docentes, es el logro y la evaluación de la atención que ponen sus estudiantes en el aprendizaje. Frente ello, nos encontramos con dos posiciones diferentes. Muchos argumentan que si no mantienen una atención exclusiva en el aprendizaje escolar, sus estudiantes no 
aprenden. Allí los relatos descalifican y tornan negativas las culturas juveniles y el uso de las TICs en el aula. Terminan sosteniendo un dilema entre la adhesión a la cultura escolar y los consumos culturales/Usos de TICs. En este contexto, algunos/as sostienen la concepción acerca de que "muchos chicos no van a estudiar a la escuela y por eso no atienden".

Cuando el docente puede identificar que un estudiante no está prestando atención a su clase, una estrategia paradigmática, ya señalada también por los jóvenes, es hacer pasar a aquél al pizarrón con la intención de "hacer juntos la tarea" (docente y estudiante). En general, el docente es consciente a los problemas que se enfrenta aquí la transmisión, en términos de "humillación del alumno frente a sus pares", bajo la categoría de burro, tal como lo discutimos antes; pero no interviene de otro modo e insiste con lo mismo.

De modo diferente a la primera posición señalada, algunos/as argumentan "los chicos prestan atención más de lo que el profesor supone", "Prestan atención simultánea a varias cosas"; aunque reconocen que no hay "atención permanente" y existen "desatenciones". Hay un momento en que la atención en los textos curriculares cede y el docente tiene que "pasar a otra cosa"13. Para validar este argumento, varios docentes refieren que evaluaron si sus alumnos habían aprendido un contenido, cuando ellos pensaban, por ejemplo, que estaban escuchando música con auriculares, y los resultados fueron afirmativos.

Desde la perspectiva de Crary (2008), podríamos pensar que esta insistencia escolar persistente acerca de la distracción de los jóvenes sobre los textos curriculares que los docentes pretenden enseñarles, no concibe que no pueda existir una dicotomía entre atención y dispersión. El autor discute que históricamente estos dos elementos forman parte de una "degradación de la atención" en la experiencia moderna; de modo que "la atención contiene en sí misma las condiciones de su propia degradación"; estaba "amenazada por su propio exceso". Es la atención misma la que convierte la "experiencia perceptiva en algo inestable y disipadora” (CRARY, 2008, p. 69).

Si profundizamos en esa fuerte oposición entre aprendizaje escolar y uso de TICs en el aula que "desviaría la atención" del primero, Buckingham (2008) nos propone considerar la relación entre escuela y tecnología, y que dicha relación significa una modificación de ambas: ¿Cómo se usa la tecnología en la escuela?, ¿existe en realidad un uso escolar y otro uso juvenil de las TICs? El autor realiza una serie de observaciones que consideramos pertinentes para nuestras discusiones. En lugar de darle "tanto poder" a la tecnología en tanto elemento perturbador en la escuela, habría que considerar los problemas que significan para la concepción del aprendizaje del docente la incorporación del uso la computadora, y la pérdida de poder que supone ello 
en la conducción de la enseñanza escolar. Además, más que preocuparse por la autonomía de las culturas juveniles que comportaría el uso de TICs en el aula, se podría analizar cómo se incluye dicho uso en el "funcionamiento social de la clase", en tanto un entorno social en el cual se inserta el uso de tecnologías. En realidad, es difícil pensar en "habilidades informáticas" juveniles separadas del dictado de contenidos curriculares en el aula. Existe una diversidad en el modo de los docentes de apropiarse del uso de TICs. Para poder incorporar dichas observaciones los docentes deberían poder aceptar cambiar sus prácticas de enseñanza en el aula. Sólo algunos de nuestros docentes estudiados, se muestran dispuestos a ello explícitamente.

La tercera cuestión, vinculada a la demanda de los/as jóvenes señalada anteriormente, es que muchos docentes discuten en sus relatos "si el chico se siente respetado y reconocido", mediante el afecto, en la relación pedagógica, en tanto una condición para el aprendizaje. Si bien estos docentes reconocen que "los chicos buscan un vínculo personalizado como en la primaria”, esto es percibido ambivalentemente por ellos. Se lo valora, pero se los considera a los estudiantes como sujetos dependientes, y se deja traslucir la concepción generalizada acerca de que la escuela media tiene que imponer normativamente una transmisión de "autonomía" a sus estudiantes: "ellos deberían estudiar solos".

\section{El uso de TICs en el contexto del aprendizaje escolar}

De análisis de lo reportado por los jóvenes y los profesores, los usos del celular y la netbook se presentan como los soportes paradigmáticos de la construcción de culturas juveniles en la escuela.

En cuanto a la disponibilidad de las netbooks, la misma es muy dispar. En general, en cada curso no más de la mitad de los jóvenes lleva las mismas a la escuela. En los motivos que explican esta situación, se destacan el miedo a que se la rompan y/o el uso familiar de la máquina. La mayoría de los estudiantes afirman que sólo algunos profesores utilizan la netbook para trabajar en clase o piden búsqueda de información ${ }^{14}$.

Si bien en todas las escuelas no está permitido el uso de netbook para juegos, música y conexión a Facebook, la mayoría de los jóvenes prefieren utilizar aquélla para estos fines.

La mayoría de los jóvenes refieren disponer de un teléfono celular. Manifiestan utilizarlo para enviar y recibir mensajes de texto, así como para escuchar música y realizar comunicaciones telefónicas (fundamentalmente a sus familiares). Finalmente algunos/as refieren utilizarlos para jugar y sacar fotos. Es de destacar que algunos/as de 
los/as jóvenes no disponen de dicho teléfono; pero a casi todos ellos les gustaría tener uno.

Pocos de los jóvenes estudiados afirman que dan a conocer o hablan de sus consumos y prácticas culturales con sus docentes en la escuela; y además pocos declaran que sus docentes les preguntan por estos consumos y prácticas. También al indagar sobre el conocimiento que tienen los docentes sobre las culturas juveniles, nos encontramos con una dificultad en la mayoría para hablar de esto. Dudan, se sienten inseguros hablando de estos temas y los perciben como algo externo y objeto de valoración, reconociendo en muchos casos que "prejuzgan". Tienen una percepción muy general y esquemática. Aunque no se siente autorizados, es de destacar, que en algunos casos tienen una aguda percepción de algunos aspectos de las culturas juveniles, fundamentalmente en lo que respecta a las estéticas corporales, y algunas prácticas de consumo vinculadas al uso de las netbooks: la conección a las redes sociales, así como a los juegos mediáticos. Todo esto es descripto, en general, en un tono de valoración negativa que opuesto al aprendizaje escolar.

No obstante ello, al mismo tiempo, algunos profesores/as argumentan que el docente tendría que conocer los "códigos culturales" juveniles para operar con ellos, en lugar de rechazar estos "códigos" y buscar imponer los códigos escolares. Se destacan en los relatos en torno a situaciones en los que los jóvenes pueden no tener límites en "cómo se habla" en la escuela frente a sus pares y con los/as profesores/as. El docente puede interpretar esto como una violencia hacia su persona y su rol. Ello generaría situaciones de violencia entre docente y estudiante y en el aula en general.

Cuando analizamos las perspectivas de los docentes sobre el uso de las TICs en el aula, destacamos las siguientes observaciones.

La primera cuestión que plantean la mayoría de los docentes es una discusión sobre la diferencia, para los jóvenes, entre "la realidad de la escuela" y la de fuera de la misma. El argumento central es: "Los chicos se sentirían poco motivados en la escuela y usan las TICs". Luego, al profundizar en este argumento encontramos diferentes posiciones. La mayoría acentúa esta oposición, y considera a las culturas juveniles como algo exterior y ajeno al aprendizaje escolar. El uso de las TICs es presentado allí, explícita o implícitamente, como algo que obstaculiza el mismo. No obstante ello, algunos docentes intentan buscar algunas mediaciones entre el aprendizaje y las culturas juveniles, afirmando que se hace necesario que exista una actualización en la formación docente acerca de la realidad cultural de los jóvenes.

Cuando profundizamos en las explicaciones de aquellos profesores que se muestran dispuestos a trabajar con las TICs en el aula, identificamos dos tipos de dificultades: 
- Aquellas que señalamos al analizar los reportes de los jóvenes, en torno a una disponibilidad de pocas netbooks en el aula, una conectividad irregular a internet, así como la incompatibilidad del Plan Sarmiento del GCBA (del cual forman parte las netbooks de los jóvenes estudiados) y el Programa Conectar Igualdad, del Gobierno Nacional (para la Escuela Media); con el cual están familiarizados estos profesores.

- Existen reglas poco claras y muy variadas en las diferentes escuelas en torno a facilitar u obstaculizar que los jóvenes lleven sus computadoras personales a la escuela. Mientras que algunas no tienen normativas explícitas que regulen esto, otras "sugieren" o "recomiendan" a las familias que sus hijos no lleven las computadoras a la escuela.

De cualquier modo, sea porque se acentúe la oposición entre uso de TICs en el aula y aprendizaje, o por estas dificultades aludidas cuando los profesores se muestran dispuestos a utilizar la netbook en sus clases, al igual que lo referido por los jóvenes, la mayoría de los profesores hace un escaso uso de estas computadoras en el aula. No obstante ello, muchos piden búsqueda de información y materiales en la red cómo tareas fuera de la escuela.

Comparando el análisis de las perspectivas de jóvenes y docentes, pudimos identificar un proceso constituido por situaciones paradigmáticas del uso juvenil de las TICs en el aula y las intervenciones docentes correspondientes. Ello podría incluir las siguientes situaciones:

- Un establecimiento inicial del profesor frente al curso, de carácter verbal, de reglas y pautas en torno al uso de la netbook y los celulares. No están permitidos durante la exposición del profesor y la realización de la tarea en forma individual y grupal. Se les advierte que de no respetar esto, se les retirará los aparatos. No obstante ello, muchos docentes consignan que si reciben una comunicación telefónica de sus padres por una urgencia pueden salir y hablar fuera del aula; así como la posibilidad de escuchar música y utilizar la computadora una vez finalizada la tarea solicitada.

- Muchos jóvenes afirman que utilizan la netbook y el celular (para mandar mensajes y escuchar música con auriculares) "a escondidas". Frente a ello, el profesor advierte que retirará los aparatos. Cuando los jóvenes no responden, el docente procede a retirar los aparatos de los estudiantes que los están utilizando. La otra respuesta docente frente a este uso de TICs, la constituye el hecho ya señalado de hacer pasar al frente al pizarrón al estudiante que no está prestando atención. 
- La “intermitencia de la atención” en clase del estudiante, entre prestar atención a la clase del profesor, y por otro, el uso del celular y la netbook junto a la interacción entre pares vinculadas a la "joda” y el "chiste”. Incluso muchos jóvenes refieren que cuando la clase les resulta aburrida pueden realizar prácticas culturales, como por ejemplo el dibujo. Es recurrente la afirmación: "me pongo a dibujar".

- El uso, aceptado por las escuelas y los docentes, de las netbooks y los celulares en la misma aula, en el momento de los recreos. En el primer caso para conectarse a Facebook, practicar algunos juegos y escuchar música; y en el segundo, para escuchar música en pequeños grupos. No obstante ello, la mayoría de los jóvenes salen del aula en los recreos y allí pueden utilizar, en general, el celular para escuchar música y/o juntarse en grupos de pares.

Es de destacar que muchos jóvenes mantienen la oposición entre desempeńo escolar y uso de TICS en el aula, para explicar el fracaso escolar. Se trata de afirmaciones del tipo: "los que escuchan música y utilizan netbook son los que van a repetir o se llevan materias"

\section{Discusión}

A partir de nuestros resultados, queremos proponer tres discusiones, que creemos necesario profundizar:

1) La masificación que comporta para los jóvenes el consumo de culturas juveniles en el ingreso a la Escuela Media no permite visualizar y podría encubrir las relaciones de violencia interpersonal $y$ desigualdad entre ellos mismos, asi como sus posiciones de productores culturales.

Las necesidades de constituir una identidad social y personal en los jóvenes se ejerce en el grupo de pares del aula mediante la violencia de diferentes variables (género, etnia, características personales, pertenencia territorial a barrios, entre otras), en contraposición de un agrupamiento juvenil en torno a consumos de medios y contenidos de subculturas juveniles.

Dicha socialización se transforma en una tensión entre, por un lado, un proceso de masificación, ejercicio de la violencia y búsqueda de eliminación de las diferencias; y por otro, un proceso de diferenciación, personalización y construcción de una posición de consumidores/productores culturales.

Cabe preguntarnos, siguiendo algunos conceptos de Guy Debord de La Sociedad del Espectáculo (apud CRARY, 2008, p. 78-79), ¿qué está significando en 
términos de subjetivación para los jóvenes la masificación y "la sociedad del espectáculo" en torno del consumo medios y uso de TICs?, ¿¿Se trata de una alienación en "imaginarios visuales" determinados o el espectáculo es una "tecnología de la separación”, una "estrategia del aislamiento" de los sujetos? Dicho de otro modo, ¿se trata de un "control visual de la atención" a través de "contenidos visuales específicos de las pantallas" o de "individualización", "inmovilización” y "separación” de los sujetos, como "formas de poder no impositivas"?

Si nos adentramos en esta segunda alternativa, el trabajo de visibilización en el aula de la diferentes formas en que opera la violencia mencionada al principio de este apartado, entre los mismos jóvenes, tiene que partir de una discusión con los ellos mismos sobre su estatuto de "sujetos culturales" que, mediante la masificación del consumo de medios, procuran "hacer a un lado", encubrir las diferencias, así como las desigualdades y relaciones de poder que se establecen entre dichas diferencias.

En contraposición a la idea de "alienación de los jóvenes en un poder de las imágenes”, Buckingham (2003) argumenta que es necesario profundizar en una serie de procesos:

1. El surgimiento de un consumidor autónomo y un sentimiento de fragmentación e individualismo, con el crecimiento masivo de los medios de comunicación y el uso de las TICs.

2. Una socialización en sociedades progresivamente más heterogéneas y multiculturales (una cohabitación de diferentes concepciones de la moralidad y tradiciones culturales muy diversas). Un cambio de las identidades y profundización de las desigualdades, en contraposición a una apariencia de las culturas de consumo y la "creencia subjetiva en la fuerza y capacidad de las personas".

3. Una profusa actividad de las culturas juveniles versus una pasividad de la escuela, circunscripta a lo que los profesores definen como "limitada atención de los niños y jóvenes en el aprendizaje”.

El problema para este autor es que los jóvenes en tanto "productores culturales" se encuentran escasamente legitimados en la escuela; si bien se puede constituir en una demanda de los mismos jóvenes y algo promovido por algunos profesores.

Según nuestros resultados, las exigencias y demandas de la cultura escolar colocan a las culturas y prácticas culturales juveniles en oposición de sentido con el aprendizaje, y se produce una disputa política entre ambos. Asimismo, dichas demandas y exigencias colocan a los jóvenes en una posición de pasividad. Hemos presentado en nuestro estudio evidencias que, bajo la mirada de la mayoría de los/as profesores/as, todas las culturas, el uso de las TICs y las prácticas culturales juveniles 
parecen ser objeto de aquello que Buckingham (2003) denomina la "sospecha modernista de la educación acerca de los medios". Allí se supone que los medios y las imágenes alienan a los/as jóvenes y los aleja de la posibilidad del conocimiento, la reflexión y el aprendizaje. Siguiendo a Ranciere (2010) el problema en estos supuestos es que para este espectador "mirar es lo contrario de conocer" y además, "ser espectador es estar separado al mismo tiempo de la capacidad de conocer y de poder actuar". Es la idea de una verdad del conocimiento a la que se debería acceder, la que estaría por fuera de las imágenes de las culturas que consumen y producen los jóvenes mismos. Dubet y Martuccelli (1999, p. 441, 448), desde el campo de la sociología de la educación, lo dicen de otro modo: "la escuela traza fronteras a los consumos culturales juveniles" y "la distancia entre la cultura de masas y la cultura escolar instala a los alumnos en dos mundos sin contactos, sin relaciones"; paradójicamente en una sociedad donde los modos de consumo cultural tienden a mezclarse y las identidades a hibridizarse.

2) En el ingreso a la escuela media, existe para los jóvenes una marcada disociación en el aula, entre por un lado, las interacciones entre pares y consumo/producción de culturas juveniles, y por otro la cultura escolary el proceso de aprendizaje.

Por un lado, los docentes demandan aprendizaje de textos curriculares según el formato de la Escuela Media; y por otro, los jóvenes, para aprender, demandan reconocimiento de su posición real de conocimientos según lo adquirido en la Escuela Primaria, y de su lugar identitário en un proceso de ingreso en las culturas de masas, así como en los problemas que comporta las nuevas sociabilidades juveniles que se conforman en el aula. El principal problema allí sería cómo el docente puede, al mismo tiempo, reconocer el mundo cultural de los jóvenes y habilitar condiciones de aprendizaje en un contexto nuevo para los jóvenes.

De nuestro análisis de las perspectivas docentes, surge que aquí se presentarían dos problemas fundamentales que estarían obstaculizando la visibilización de las culturas juveniles, muy vinculadas entre sí. Por un lado, aun cuando se reconocen las prácticas y culturas juveniles en la relación pedagógica y en la escuela en general, los/as docentes establecen una oposición dilemática entre éstas y el aprendizaje escolar, que torna negativas, abstrae y coloca la presencia real de dichas prácticas y culturas juveniles en una relación de exterioridad con dicho aprendizaje. El segundo problema, sería que al colocar éstas en una relación de exterioridad, ellas no terminan de constituir un "no saber", un obstáculo, en la práctica pedagógica misma. El principal indicador de ello, es que pocos docentes manifiestan alguna inquietud e interés por conocer el mundo cultural del que participan sus estudiantes, y que la mayoría no les preguntan para "reconocerlos", sin la performatividad que le impone a los jóvenes el formato escolar. 
También Buckingham (2003), propone profundizar en la autoridad de los medios de comunicación sobre los jóvenes, y en el dilema entre autoridad del docente y la autonomía cultural juvenil. Es necesario un reconocimiento y puesta en discusión de las diferencias entre el valor de los medios para la vida de los profesores y los jóvenes. ¿Cuáles son las nociones de representación, significado e identidad, que se ponen en juego en la relación pedagógica? ¿"seriedad”?, ¿ “juego”?, ¿"parodia”?, ¿"ironía”?.

Podríamos argumentar aquí que el problema de la autoridad del docente se juega en dos movimientos. Por un lado, en términos de un reconocimiento y delimitación de mundos culturales diferentes en el aula, sin que ello signifique en sí mismo un ejercicio de poder que jerarquice un mundo cultural sobre otro. Si dicho reconocimiento no se produce y dichas jerarquías se hacen evidentes, la violencia se hace presente como mecanismo de poder de disputa de sentido, pero también como una lucha ética en términos de búsqueda de reconocimiento de los mundos culturales que están presentes en la escuela; dejando una pregunta abierta al otro en términos intersubjetivos, sobre la visibilización de la propia realidad cultural de cada uno de los actores institucionales. Pero esto aún no alcanza. Es necesario un segundo movimiento: que a partir de esa acción de reconocimiento del docente, éste pueda crear condiciones de aprendizaje y transmisión; las que procuren incorporar los mundos culturales juveniles, aunque siempre se mantengan en tensión por la disputa de sentido con la propuesta pedagógica escolar.

3) La problemática de atención/desatención de los jóvenes en el proceso de aprendizaje en el aula, está vinculada con el proceso de transmisión que se produce entre docentes y estudiantes en el ingreso a la Escuela Media.

Tanto los jóvenes como los docentes estudiados demandan que los primeros aprendan. Hemos discutido en nuestros hallazgos que los jóvenes les reclaman a sus profesores un reconocimiento de sus identidades culturales como condición del aprendizaje escolar en el aula. No rechazan, ni estarían "desinteresados" porque estos adultos les enseñen conocimientos, sino que cuestionan las condiciones de transmisión supuestas que busca imponer el docente. Muchos estudios ya han señalado que tradicionalmente las prácticas de enseńanza de la escuela responden a una "transmisión secuencial de la información”, la que configura alumnos que deberían incorporar el conocimiento por "procedimientos pautados y sucesivos" según una lógica racional (SCHAEFER, 2012).

La problemática de la atención/desatención en el aula no puede desvincularse, de la presencia efectiva allí mismo de los repertorios culturales, las diversas formas en que los jóvenes consumen/producen imágenes y los conocimientos disponibles que adquirieron en su escolaridad primaria. Todo esto cuestiona esa "transmisión secuencial 
de información" y configura diferentes temporalidades que los docentes tendrían dificultades de reconocer para incorporarlas de algún modo al proceso de transmisión para el proceso de aprendizaje. Se trata del no reconocimiento de varios elementos: las identidades culturales juveniles como parte de los sujetos de educación y la "alfabetización digital que cuestiona la cultura letrada escolar, pero que la incorpora de otro modo: se lee la palabra en la imagen" (KRESS, 2005, p. 29); los conocimientos reales adquiridos en la escolaridad primaria; las categorías meritocráticas, como la de burro, que reproducen e interiorizan en los jóvenes el fracaso y la repitencia escolar.

Y también se trata de uno de los principales problemas en la transmisión: una tensión permanente que enfrenta el docente entre tener que responder a las demandas personalizadas de aprendizaje de los jóvenes, y por otro, optar entre continuar reproduciendo un conocimiento impersonal para todos, o crear condiciones para recuperar de algún modo condiciones de aprendizaje colectivo. Donde, al mismo tiempo, cada joven pueda sentirse interpelado personalmente.

La problemática de la transmisión se transforma así en una interpelación de la "cultura de la imagen" a las "gramáticas" y "formas escolares". Y, uno de los principales desafíos allí, es abordar la pérdida de "cultura común" que ha sufrido la cultura letrada en el horizonte humanista frente a los cambios en la cultura de la imagen y el lugar de la misma en la alfabetización ¿Qué es lo que podemos caracterizar hoy como cultura común entre jóvenes y adultos en la escuela? (DUSSEL, 2009)

Pensamos que una política en la escuela que se interese por buscar una vinculación del aprendizaje escolar con las culturas y consumo/producción de imágenes juveniles, podría profundizar en una serie de dimensiones:

- La capacidad de la dimensión institucional de las escuelas para problematizar su propio ámbito como territorio simbólico de disputa de sentido en el proceso de transmisión en el aula, donde confluyen el dictado curricular del docente, y el uso de TICs, las culturas y prácticas culturales juveniles.

- Los procesos de reconocimiento de los mundos culturales diferentes que intervienen en la relación pedagógica.

- Las posibilidades de cada docente en particular de establecer mediaciones entre los contenidos curriculares, y por otro lado, las sociabilidades juveniles y el uso de TICs en el aula.

- Las diferentes formas de los jóvenes de colocarse en transmisión con las propuestas de sus profesores. 


\section{Notas}

${ }^{1}$ Proyecto "Culturas juveniles, transmisión y relaciones de generación: los jóvenes y la construcción de identidades en el ingreso a la Escuela Media”, realizado con sede el Consejo de Investigación en Salud/Ministerio de Salud/GCBA, entre 2012 y 2013.

${ }^{2}$ Se trabajo con jóvenes y docentes provenientes de 7 escuelas medias (de modalidades técnica y bachiller), así como de una ONG que trabaja en apoyo escolar a nivel territorial en un barrio.

${ }^{3}$ Tres de los grupos se realizaron en divisiones de primer año de una misma escuela, en el espacio curricular de "Taller de ingreso" y uno fue realizado en un espacio comunitario de apoyo escolar en un barrio en particular.

${ }^{4}$ En un trabajo previo, hemos discutido el estatuto de sujeto de la educación del joven que ingresa a la Escuela Media en las concepciones de estos/as mismos/as docentes, en términos de una exigencia de ajuste de los jóvenes a una autonomía ya supuesta. Esta opera fuertemente en la relación pedagógica multiplicando las demandas a éstos, pero sin visibilizar las necesidades y el proceso de cambio que están transitando (VILLA, 2012).

${ }^{5}$ Es importante destacar que esta suerte de "identidad barrial" de los jóvenes, en los espacios educativos comunitarios de un mismo barrio no genera estos conflictos de socialización que se presentan en el espacio escolar. Por el contrario, hemos observado que en el grupo de discusión de jóvenes de un mismo barrio en un espacio educativo comunitario, la sociabilidad común del mismo barrio va en la misma dirección de las necesidades educativas, e incluso ambas pueden complementarse. Reafirman nuestra observación la mayoría de las opiniones de referentes de espacios socioeducativos y culturales que trabajan con jóvenes, los cuales entrevistamos para este mismo estudio.

${ }^{6}$ En un trabajo previo hemos discutido esta concepción docente que hace depender en forma independiente las posibilidades de socialización y de educabilidad de los/as jóvenes, del capital social y cultural de las familias de procedencia de los/as mismos/as. Hemos observado que esta concepción abstrae y encubre el lugar del docente y la escuela como actores de dicha socialización y garantes de la educabilidad (VILLA, 2012).

7 Esto está vinculado a los efectos de las políticas educativas de "inclusión social" orientadas a los jóvenes de los sectores populares en el nivel medio, que desdibuja la función de enseñanza de conocimientos de la escuela y los docentes (VILLA, 2012).

${ }^{8}$ Es importante mencionar que esta pregunta fue trabajada en los grupos de discusión en el primer trimestre de la escolarización del primer año de la Escuela Media; lo que haría suponer una escasa "impregnación de la cultura escolar". También no debemos dejar de tener en cuenta que en aquellos/as jóvenes entrevistados en la finalización del primer año se encontró una posición más reflexiva sobre los cambios experimentados a lo largo de casi toda la trayectoria educativa de ese año. Finalmente, al evaluar con los docentes 
tutores el proceso de los grupos de discusión en el aula, observamos que muchos jóvenes no mostraban interés en reflexionar sobre experiencias, con que estaban aconteciendo en sus socialización escolar, caracterizadas por conflictos en el grupo de pares, con sus docentes y con la institución escolar. Ello supone un problema teórico metodológico que excede los límites de este trabajo, pero que es necesario señalar.

${ }^{9}$ Como veremos más adelante, esta intermitencia está vinculada al uso de la TICs en el aula.

${ }^{10}$ Esta categoría alude a una condición esencial, peyorativa y despectiva de alguien que está imposibilitado de poder aprender conocimientos.

11 Habría que profundizar en los sentidos que puede adquirir esta categoría en la transmisión de docentes con estudiantes. En principio alude a un texto que no sea extenso y que no se torne a "aburrido". El "hablar poco" para que algo del docente se escuche. Pero ello no alcanza para definir lo que está aconteciendo en un sentido más amplio en la relación pedagógica, lo que pueda tornarse escuchable o no.

${ }^{12}$ Es necesario profundizar en la discusión acerca de las posibilidades de que el grupo en el aula se constituya como un colectivo en la transmisión pedagógica, frente a esta persistente demanda de los/as jóvenes de una relación uno a uno con sus docentes. Es importante destacar que esta demandas juveniles, en muchos/as jóvenes encuentran respuestas en los espacios de apoyo escolar de la modalidad de "uno a uno" (un joven y un profesor), en el trabajo que realizan ONGs a nivel territorial en diferentes barrios.

13 En un estudio previo hemos destacado que estos profesores, buscan regular el tiempo de la atención que pueden prestar los estudiantes a los contenidos de sus asignaturas (VILLA, 2012).

${ }^{14}$ Como veremos más adelante, ello, en parte, está vinculada a que los profesores afirman que ellos desconocen el software de las netbooks del Plan Sarmiento, que proviene de un plan municipal de la Ciudad de Buenos Aires para la escuela primaria y que es incompatible con el programa Conectar Igualdad del Gobierno Nacional, para la escuela media; el que entrega los aparatos a partir del $2^{\circ}$ año.

\section{REFERÊNCIAS}

BARBERO, Jesus Martín. Experiencia audiovisual y desorden cultural. In: BARBERO, Jesus Matín; ROCHE, Fabio Lopez de la (Ed.). Cultura, medios y sociedad. Bogotá: Universidad Nacional de Colombia, 1998. p. 27-64.

BUCKINGHAM, David. La educación en medios de comunicación y el fin de consumidor crítico. In: JORNADAS TÉCNICAS DEL PROYECTO EDUCATIVO DE CIUDAD “COMUNICAR Y EDUCAR”, 3., 2002, Barcelona. Actas... Barcelona: OIE, 2002. Disponible en: <http://www.oei.es/valores $2 /$ monografias/monografia01/reflexion02.htm\#1a>. Acceso en: jul. 2003. 
BUCKINGHAM, David. Más allá de la tecnología: aprendizaje infantil en la era de la cultura digital. Buenos Aires: Manantial, 2008.

CRARY, Jonathan. Suspensiones de la percepción: atención, espectáculo y cultura moderna. Madrid: Akal, 2008.

DUBET, Francois; MARTUCCELLI, Danilo. En la escuela: sociología de la experiencia escolar. Buenos Aires: Losada, 1999.

DUSSEL, Inés. Escuela y cultura de la imagen: los nuevos desafíos. Nómadas, Bogotá, n. 30, p. 180-193, abr. 2009

GARCIA CANCLINI, Nestor. Consumidores y ciudadanos. Conflictos multiculturales de la globalización. México: Grijalbo, 1995.

IBANEEZ, Jesus. El regreso del sujeto: la investigación social de segundo orden. Madrid: Siglo XXI de España, 1994.

KRESS, Gunther. El alfabetismo en la era de los nuevos medios de comunicación. Málaga: Enseñanza Abierta de Andalucía y Ediciones Aljibe, 2005.

MILES, Matthew B.; HUBERMAN, Michael. Qualitative data analysis. California: Sage, 1994.

MINISTERIO DE EDUCACIÓN-PRESIDENCIA DE LA NACIÓN. Consumos culturales digitales: jóvenes de 13 a 18 años. Buenos Aires: Ministerio de Educación de la Nación, 2012.

RANCIÈRE, Jacques. El espectador emancipado. Buenos Aires: Manantial, 2010.

SCHAEFER, Verónica Plaza. TIC, escuelas y jóvenes: la producción de medios de comunicación en los procesos educativos. In: VILLA, Alejandro; INFANTINO, Julieta; CASTRO, Graciela (Org.). Culturas juveniles: disputas entre representaciones hegemónicas y prácticas. Buenos Aires: NOVEDUC-ReIJA, 2012. p. 141-159.

VILLA, Alejandro. Cuerpo, relaciones de género y de generación: perspectivas biográficas e histórico-culturales en el campo de la educación. In: VILLA, Alejandro (Org.). Sexualidad, relaciones de género y de generación: perspectivas histórico-culturales en educación. Buenos Aires: Novedades Educativas, 2009. p. 85-135.

VILLA, Alejandro. Las concepciones y los problemas de la transmisión generacional en la transición de la Escuela Primaria a la Media. In: JORNADAS DE SOCIOLOGÍA DE LA UNLP, 7., 2012, La Plata. Actas... La Plata: UNLP, 2012.

VILLA, Alejandro; INFANTINO, Julieta; CASTRO, Graciela. Introducción. In: VILLA, Alejandro; INFANTINO, Julieta; CASTRO, Graciela (Org.). Buenos Aires: NOVEDUC-ReIJA, 2012. p. 11-24. 


\section{As condições de aprendiza- gem escolar, as culturas juve- nis e o uso das TICs no ingresso do Ensino Médio: o problema da transmissão entre os jovens e os professores}

\section{Resumo}

No presente artigo se estuda as problemáticas da relação entre as culturas juvenis e a aprendizagem, assim como os processos de transmissão entre os jovens estudantes e os professores no primeiro ano do Ensino Médio. Trata-se de uma pesquisa qualitativa de casos estudados em profundidade, na qual se realiza uma comparação entre os jovens estudantes e os professores. Utilizam-se técnicas de entrevistas semiestruturadas e o grupo de discussão. Os objetivos gerais são os de explorar e descrever os significados que adquirem para as identidades juvenis a incorporação dos meios de comunicação massiva, assim como o consumo e produção de culturas juvenis e o impacto que introduzem os ditos significados nos processo de transmissão geracional entre os docentes e os jovens estudantes. A partir dos resultados, propõem-se três eixos de discussóes: a massificação que comporta para os jovens o consumo de culturas juvenis no primeiro ano do Ensino Médio não permite visualizar e poderia ocultar as relaçóes de violência interpessoal e de desigualdade entre eles, assim como suas posiçôes de produtores culturais; existe para os jovens uma marcada dissociação na aula, entre, por um lado, as interaçôes entre pares e o consumos/produção de culturas juvenis, e, por outro, a cultura escolar e o processo de aprendizagem; a problemática de atenção/desatenção dos jovens no processo de aprendizagem na aula está vinculada ao processo de transmissão que se produz entre os docentes e os estudantes no ingresso á Escola Média.

Palavras-chave: Pedagogia. Culturas Juvenis. Ensino Médio.
The conditions of school learning, youth cultures and the use of ICTs in entering high school: the problem of transmission among young people and teachers

\section{Abstract}

In the present paper that comprises the problems of the relation between young cultures and learning are studied, as well as the transmission problems between young people and teachers, in the first year of Middle School. It is a qualitative research which studied deeply some cases. The research makes a comparison among young students and teachers. We use two techniques of research: the semi structured interview and the discussion group. The general objectives are explore and describe the meanings that the incorporation of mass media of communication gets for the for young identities, as well as the consumption and production of young cultures and the impact which introduces their meanings into the generational transmition process between teachers and young people. From our results, we propose three discussion axes: the massification which involves for young people the consumption of young cultures in the first year of Middle School, does not allow visualize, and it could cover up interpersonal violence relations and inequality among themselves as well as their positions of cultural producers; it does exist for young people a marked dissociation in the classroom: on one side, there are the interactions between the group members and consumption/production of young cultures, and, on the other side, the school culture, and the learning process; the problem of attention/inattention of young people in the learning process in the class, is linked to the transmission process, which is produced between teachers and students in the entry into the Middle School.

Keywords: Pedagogy. Youth Cultures. Middle School. 


\section{Alejandro Villa}

E-mail: alejandrovilla2001@yahoo.com.ar

Recebido em: 11/11/2014 Aprovado em: 21/02/2015 

ARTIGOS DE DEMANDA CONTÍNUA 
